\title{
ANALISIS USAHA TANAMAN HIAS \\ DI KELURAHAN TEMBILAHAN KOTA KECAMATAN TEMBILAHAN \\ KABUPATEN INDRAGIRI HILIR \\ (Studi Kasus Kembang Lestari Garden)
}

\author{
Partini Partini ${ }^{1}$, Nuraini1 \\ 1Program Studi Agribisnis Fakultas Pertanian UNISI \\ Email: green tien2@yahoo.com
}

\begin{abstract}
ABSTRAK
Salah satu komoditas pertanian yang digunakan untuk keindahan adalah tanaman hias. Tujuan penelitian ini adalah : (1) Untuk mengetahui biaya yang dikeluarkan dalam usaha tanaman hias Kembang Lestari Garden. (2) Untuk mengetahui pendapatan yang diperoleh dalam usaha tanaman hias Kembang Lestari Garden. (3) Untuk mengetahui efesiensi dalam usaha tanaman hias Kembang Lestari Garden. Hasil penelitian ini menunjukkan bahwa : (1) Total biaya yang dikeluarkan sebesar Rp.11.245.766. (2) Pendapatan bersih sebesar Rp. 2.164.234. (3) Efesiensi usaha tanaman hias adalah Rp. 1,21 berarti setiap Rp.1,biaya yang di keluarkan memberikan penerimaan sebesar Rp. 1,21 keuntungan sebesar Rp. 0,21.
\end{abstract}

Kata Kunci : Analisis Usaha, Tanaman Hias

\begin{abstract}
One of the agricultural commoity used for decoration is an ornamental plant. The purposes of this study are : (1) To know the cost incurred in the business of ornamental plants in KembangLestary Garden. (2) To know the income in the business of ornamental plants in Kembang Lestari Garden. (3) To know the efficiency in the business of Ornamental Plant in Kembang Lestari Garden. The results of this study show that : (1) Total cost incurred Rp.11.245.766/Period and net income of Rp. 2.164.234/Period (2) The result of the efficiency of the ornamental plant business is Rp. 1,21 means every Rp.1, the cost incurred gives a receipt of Rp. 1,21 and profit receipt of Rp. 0,21.
\end{abstract}

Keywords : Business Analysis, Ornamental Plants

\section{PENDAHULUAN}

Tanaman hias yang berdayasaing tinggi diperlukan cara meningkatkan suatu kuantitas dan kualitas dari tanaman hias tersebut sehingga menghasilkan suatu produk 
yang ekonomis serta dalam hal penataan penanaman dapat mengatur dan memilih jenis tanaman yang dibudidayakan dalam bedengan tanah selama jangka waktu tertentu sehingga tanaman hias dapat bervariasi dari jenis tanaman sebelumnya, apabila tanaman dibuat bervariasi sedemikian rupa maka harga akan lebih tinggi, dan kesejahteraan yang lebih baik (Wulandari, 2008).

Salah satu usaha tanaman hias yang cukup berkembang di Tembiahan Kota adalah usaha Kembang Lestari Garden. Usaha ini berdiri sejak tahn 2007 yang didirikan oleh bapak M.Rizal yang berusia42 tahun, lokasi usahanya terletak disamping rumah pemilik usaha dengan luas lahan $25 \times 20 \mathrm{~m}$, dan didepan rumah pemilik usaha yaitu 10x15m.Usaha ini pada awalnya dilaksanakan dengan mencoba menanam sedikit tanaman hias, dikarenakan ada lahan yang kosong disamping rumah pemilik usaha tanaman hias sehingga semakin berkembang dan menarik minat konsumen pemilik usaha pun tertarik untuk lebih mengembangkan usahanya hingga saat ini.

Jenis tanaman yang ada pada lokasi penelitian yaitu mulai dari tanaman hias, tanaman obat-obatan sampai tanaman buah-buahan, namun yang paling banyak dikembangkan dan diperjual belikan pada tempat usaha ini adalah tanaman hias, tanaman obat-obatan dan buah-buahan hanyalah sedikit saja.Kegiatan yang dilakukan pada tempat usaha tanaman hias ialah melakukan penjualan langsung kepada konsumen, biasanya tanaman hias yang telah diproduksi langsung dijual kepada konsumen.

\begin{abstract}
Permasalahan dalam berbisnis tanaman hias adalah persaingan yang terjadi saat penjualan seperti adanya pemilik usaha dari luar daerah Tembilahan melakukan penjualan tanaman hias juga sehingga sepinya konsumen yang datang, besarnya biaya produksi yang dikeluarkan dalam perawatan tanaman sebelum di beli oleh konsumen, dan hambatan lainnya adalah sulitnya mendapatkan bibit tanaman yang didatangkan dari luar daerah Tembilahan, terkadang bibit yang telah dipesan oleh pemilik usaha Kembang Lestari Garden lama datangnya sehingga stok tanaman yang sudah berkurang belum terganti oleh tanaman baru. Tujuan penelitian ini adalah untuk mengetahui biaya yang dikeluarkan, untuk mengetahui pendapatan yang diperoleh dan untuk mengetahui efesiensi dalam usaha tanaman hias Kembang Lestari Garden.
\end{abstract}

\section{TINJAUAN PUSTAKA}

\subsection{Tanaman Hias}

Tanaman hias merupakan tumbuhan yang biasa ditanam orang sebagai hiasan.Umumnya pengertian hiasan adalah hiasan didalam rumah, atau taman-taman umum, otomatis ukuran tanaman tidak terlalu besar dan rimbun.Pada umumnya tanaman hias dapat digolongkan menjadi tanaman hias bunga dan tanaman hias daun.Tanaman hias bunga merupakan tanaman hias dengan bagian bunganya yang menarik.Adapun tanaman hias daun merupakan tanaman daun yang menarik. (Prihmantoro, 1997)

Tanaman hias memiliki kisaran harga yang beragam, yaitu dari puluhan ribu hingga ratusan juta rupiah.Penentuan harga ditentukan 
oleh tren yang berkembang Selain penjualan, bisnis tanaman hias juga diramaikan dengan usaha penyewaan tanaman. Konsumen yang dituju adalah hotel, kantor, rumah sakit dan restoran hingga pusat perbelanjaan. Bahkan kini pengusaha rental tanaman hias juga memasarkan ke event dekorasi seminar, pameran dan perkawinan.(Wulandari, 2008).

Tanaman hias dapat dipergunakan sebagai dekorasi baik dalam ruangan maupun luar ruangan. Tanaman hias memiliki berbagai macam jenis mulai dari tanaman berbunga sampai tanaman yang berbentuk unik. Bentuk tanaman ini sangat beraneka ragam dan masingmasing tanaman memiliki daya tarik tersendiri untuk layak dikoleksi. Tanaman hias juga dapat dipakai sebagai hiasan, tanaman ini dapat diletakkan diberbagai tempat seperti didepan rumah, ruang tamu dan lainlain.

Jumlah tanaman hias yang umum tidak dapat dihitung secara pasti karena banyak tanaman liar yang kini digolongkan sebagai tanaman hias. Selain itu dengan adanya tanaman yang didatangkan dari luar negeri menambah kekayaan akan tanaman hias, adanya kemajuan dan teknologi sekarang manusia sering melakukan persilangan jenis tanaman yangmenghasilkan tanaman baru. Sebab itu jenis tanaman hias semakin bertambah banyak (Trubus, 1998).

\subsection{Usahatani}

Menurut Mosher (1987) Usahatani dapat disebut sebagai suatu cara hidup jenis ini termasuk usahatani seperti pada saat sekarang sudah langka ditemui. Pada saat sekarang pada umumnya jenis usahatani yang termasuk perusahaan. setiap petani pada hakekatnya menjalankan perusahaan pertanian diatas usahataninya. Itu merupakan bisnis karena tujuan setiap petani bersifat ekonomis, memproduksi hasil-hasil untuk dijual kepasar atau untuk dikomsumsi sendiri oleh keluarganya. Usahatani tanaman hias yang bertujuan ekonomis termasuk usahatani perusahaan.

Dalam menjalankan suatu usahatani, petani memerlukan sejumlah biaya. Biaya usahatani adalah nilai dari semua yang di perlukan yang dapat di ukur, biaya produksi ini terdiri dari: Sarana produksi yang habis terpakai, bunga modal, sewa tanah (lahan), alat produksi yang tahan lama, tenaga kerja, upah pengelola. (soekartawi, 2002 ).

Sarana produksi yang habis terpakai misalnya : bibit, pupuk, dan pestisida. Biaya bunga modal ( interest ) adalah bunga modal yang di gunakan untuk usaha tani sebesar bunga uang di bank. Baik modal sendiri atau modal pinjaman (kredit) diperhitungkan biaya bunga modal. Biaya tanah (lahan) adalah sewa yang akan diterima jika tanah tersebut di sewakan kepada orang lain. Tanah adalah faktor produksi yang tidak luas, bahkan nilai tanah semakin lama semakin naik. Karena itu diperhitungkan biaya sewa tanah, baik tanah milik sendiri maupun di kontrakkan. Biaya produksi yang tanah lama di hitung melalui biaya penyusutan. Biaya ini bergantung pada nilai pembelian alat dan jangka usia ekonomis alat (boleh juga diperhitungkan nilai sisa alat itu). Biaya tenaga kerja sendiri dari biaya tenaga kerja dalam keluarga ( TKDK ) dan tenaga biaya kerja luar keluarga (TKLK). 


\subsection{Produksi}

Kegiatan

produksi

merupakan proses transformasi masukan menjadi suatu keluaran. Jadi kegiatan produksi adalah melaksanakan rencana produksi yang telah dibuat dan merupakaan kegiaatan yang mempunyai proses produksi berdasarkan masukan, baik langsung maupun tidak langsung untuk menghasilkan produk (Sa'in, 2004).

Proses produksi dalam agribisnis menjadi suatu kegiatan yangsangat menentukan keberhasilan usaha dan merupakan penyedot biaya yang paling besar. Dengan demikian, kegiatan produksi tersebut harus dilakukan secara efektif dan efesien untuk mencapai produktifitas yang tinggi. Efektifitas kegiatan produksi dapat dilihat dari alokasi sumber daya yang benar, perencanaan proses produktifitas yang benar, serta pelaksanaan yang benar. Dilain pihak efesiensi proses produksi dapat dicapai dengan melaksanakan rencana dan proses produksi yang dengan benar dan meminimalkan pemborosan-pemborosan selama proses produksi berlangsung, baik pemborosan sumber daya, waktu dan tenaga maupun pemborosan karena kehilangan dan kerusakan produksi (Sa'id, 2004).

\subsection{Pendapatan}

Pendapatan dapat dibagi menjadi dua, yaitu sebagai berikut:

1. Pendapatan kotor, yaitu seluruh pendapatan yang di peroleh petani dalam usaha tani selama satu tahun yang dapat di perhitungkan dari hasil penjualan atau pertukaran hasil produksi yang di nilai dalam rupiah berdasarkan harga persatuan berat pada saat pemungutan hasil.

2. Pendapatan bersih, yaitu seluruh pendapatan yang di peroleh petani dalam satu tahun di kurangi dengan biaya produksi selama proses produksi. Biaya produksi meliputi biaya riil tenaga kerja dan biaya sarana produksi.

3. Pendapatan kerja keluarga adalah pendapatan petani yang dikurangi dengan bunga modal sendiri yang merupakan pendapatan sendiri tenaga kerja keluarga dinyatakan dalam jumlah uang untuk satu hari kerja (Hadisapoetro, 1973).

\subsection{Efesiensi}

Menurut Soekartawi (1995), efesiensi usaha dapat dihitung dari perbandingan antara besarnya penerimaan dengan biaya yang dikeluarkan untuk berproduksi, yaitu dengan menggunakan $\mathrm{R} / \mathrm{C}$ dibagi dua, yaitu $\mathrm{R} / \mathrm{C}$ yang menggunakan biaya yang riil dikeluarkan pengusaha dan $\mathrm{R} / \mathrm{C}$ yang menghitung semua biaya, baik biaya yang riil dikeluarkan maupun biaya yang tidak riil dikeluarkan.

Menurut Rahardi (1999), bahwa $\mathrm{R} / \mathrm{C}$ rasio menunjukkan pendapatan kotor (penerimaan) yang diterima untuk setiap rupiah yang dikeluarkan untuk memproduksi, sekaligus menunjang kondisi suatu usaha. perkiraan kondisi tersebut sangat penting karena dapat dijadikan penilaian terhadap keputusan pengusaha dan kemungkinan pengembangan usaha tersebut.Tujuan utama dari suatu usaha adalah memperoleh pendapatan yang besar, disamping tujuan yang lebih utama adalah 
mencapai suatu tingkat efesiensi yang tinggi.

\section{METODOLOGI PENELITIAN}

\subsection{Tempat dan Waktu penelitian}

Penelitian dilakukan di tempat usaha tanaman hias Kembang Lestari Garden, kerenatempat usaha tersebut cukup berkembang di Tembilahan Kota Baik pada bidang usahatani dan penjualan kepada konsumen. Penelitian ini dilakukan bulan April 2017 sampai bulan Juni 2017.

\subsection{Jenis dan Sumber Data}

Jenis dan sumber data yang digunakan adalah sebagai berikut :

1. Data primer adalah data yang di ambil langsung dari responden melalui koesioner dan dokumentasi dilapangan, yaitu data yangmeliputi biaya, produksi, modal, dll.

2. Data skunder adalah data yang sudah jadi, di kumpulkan dan di olah oleh pihak lain, yaitu meliputi catatan atau dokumentasi pemilik usaha tanaman hias.

\subsection{Metode Analisis Data}

\subsubsection{Analisis Biaya usahatani}

Biaya usahatani adalah seluruh pengeluaran dana yang diperhitungkan untuk keperluan usaha, Biaya yang digunakan oleh pemilik usaha tanaman hias adalah seperti biaya pembelian pupuk, bibit, pestisida.

$$
\mathrm{TC}=\mathrm{FC}+\mathrm{VC}
$$

Dimana:

$$
\begin{array}{ll}
\mathrm{TC} & =\text { Total Biaya }(\mathrm{Rp} / \mathrm{bln}) \\
\mathrm{FC} & =\text { Biaya Tetap }(\mathrm{Rp} / \mathrm{bln})
\end{array}
$$

$\mathrm{VC}=$ Biaya Variabel $(\mathrm{Rp} / \mathrm{bln})$

\subsubsection{Penyusutan Alat}

Untuk menghitung biaya penyusutan alat dalam usahatani di hitung dengan metode garis lurus menurut Sinuraya (1985). Dengan rumus sbb :

Keterangan :

$$
=\frac{\mathrm{C}-\mathrm{SV}}{\mathrm{UL}}
$$

$\mathrm{D}=$ Nilai penyusutan alat

(Rp/unit/Tahun)

$\mathrm{C}=$ Harga beli alat (Rp)

$\mathrm{SV}=$ Nilai sisa alat $(20 \%$ dari nilai beli)

$\mathrm{UL}=$ Masa pakai alat (Tahun)

\subsubsection{Analisis Pendapatan Kotor}

Untuk menghitung pendapatan bersih usahatani terlebih dahulu harus diketahui pendapatan total dan pengeluaran pada periode tertentu. Pendapatan total petani didekati dengan persamaan sebagai berikut (Boediono, 1993 ).

$$
\mathrm{TR}=\mathrm{P} \times \mathrm{Q}
$$

Keterangan :

TR =Pendapatan total petani (Rp).

$\mathrm{P} \quad=$ Price $(\mathrm{Rp} / \mathrm{Btg})$

$\mathrm{Q} \quad=$ Quantitas (batang)

Pendapatan kerja keluarga
dengan menggunakan rumus
menurut Hermanto (1991), yaitu:

$$
\mathrm{PKK}=+\mathrm{K}+\mathrm{D}
$$

Keterangan :

PKK =Pendapatan kerja keluarga (Rp/Bln) 


$$
\begin{aligned}
& \mathrm{rr}=\text { Pendapatan Bersih } \\
& (\mathrm{Rp} / \mathrm{Bln}) \\
& \mathrm{K} \quad=\text { Upah tenaga kerja dalam } \\
& \text { keluarga }(\mathrm{Rp} / \text { Bln }) \\
& \mathrm{D}=\text { Depresiasi }(\mathrm{Kg})
\end{aligned}
$$

\subsubsection{Analisis Pendapatan bersih}

Pendapatan bersih usahatani dalam menganalisis pendapatan digunakan rumus yaitu:

$$
\Pi=\mathrm{TR}-\mathrm{TC}
$$

Keterangan:

II = Pendapatan Bersih

$\mathrm{TR}=$ Total Penerimaan $(\mathrm{Rp} / \mathrm{Bln})$

$\mathrm{TC}=$ Total Biaya (Batang)

\subsubsection{Efesiensi}

Untuk mengukur efesiensi usahatani digunakan rumus analisis $\mathrm{R} / \mathrm{C}$ sebagai berikut:

$$
\mathrm{R} / \mathrm{C}=\frac{\mathrm{TR}}{\mathrm{TC}}
$$

Keterangan:

$\mathrm{TR}=$ Total Revenue (Penerimaan Total) (Rp/Bln)

$\mathrm{TC}=$ Total Cost (Biaya

Total)(Rp/Bln)

Dengan Kriteria;

$\mathrm{R} / \mathrm{C}>1=$ Berarti Usaha tani Tanaman

Hias menguntungkan.

$\mathrm{R} / \mathrm{C}<=$ Berarti usaha tani Tanaman

Hias tidak menguntungkan.

$\mathrm{R} / \mathrm{C}=1=$ Berarti usaha tani Tanaman

Hias berada pada titik impas.

\section{HASIL DAN PEMBAHASAN}

\subsection{Faktor-faktor Produksi}

\subsubsection{Tempat Usaha}

Dalam melakukan suatu usaha tentunya harus mempunyai suatu lahan dalam mengelola usahanya baik itu lokasi usaha yang dekat dengan rumah pemilik usaha maupun jauh, lahan usaha sangat berpengaruh dalam melakukan usaha tanaman hias, pemilik usaha tanaman hias pada tempat penelitian memiliki tempat usaha yang strategis yaitu tepat di samping rumah pemilik usaha dan lahan kedua berlokasi di depan rumah pemilik usaha.

\subsubsection{Modal}

$\begin{array}{rrr}\text { Suatu } & \text { usaha } & \text { yang } \\ \text { berkembang } & \text { tentunya } & \text { sangat } \\ \text { membutuhkan } & \text { modal } & \text { dalam }\end{array}$ membiayai kegiatan usaha yang sedang berjalan dalam mendapatkan investasi dan keperluan lainnya. Menurut Ardi Nugraha (2011) modal usaha adalah uang yang dipakai untuk berdagang yang dapat dipergunakan untuk menghasilkan sesuatu kekayaan baik dalam bentuk uang maupun barang yang digunakan untuk menghasilkan sesuatu secara langsung maupun tidak langsung dalam proses terjadinya produksi. Di dalam produksi tentunya memerlukan sebuah alat yang dapat membantu proses produksi suatu usaha, pada usaha Tanaman Hias Kembang Lestari Garden memerlukan alat sebagai berikut :

a. Shade net

Shade net adalah jaring yang terbuat dari plastik / senar dengan intensitas kerapatan tertentu, yang berfungsi untuk menjaga tanaman dari efek penyinaran langsung dari matahari, mengurangi cahaya yang masuk ke lahan/tanaman.

b. Papan

Papan yang digunakan pada usaha kembang lestari garden adalah sebagai lantai untuk mendudukkan pot bunga, disamping itu papan pada usaha tanaman hias juga di gunakan 
sebagai ajir atau tiang untuk berdirinya tanaman yang berjalar.

c. Skop

Skop pada usaha tanaman hias adalah digunakan sebagai penyendok tanah dan pengaduk antara tanah dan pupuk kandang/kompos sebelum dimasukkan ke dalam pot bunga.

d. Cangkul

Cangkul digunakan untuk mencangkul tanah dan membuat dataran yang sedikit tinggi/bedengan apabila tanaman ada yang terkena banjir.Cangkul juga dapat berfungsi dalam mengaduk tanah apabila dalam jumlah banyak.

e. Gembor

Gembor merupakan alat yang sangat membantu dalam pengelolaan tanaman hias, pada usaha tanaman hias gembor di gunakan untuk menyiram bunga pada tanaman tergantung pada kebutuhan air setiap tanaman.

\section{f. Gunting Stek}

Gunting stek adalah alat yang di gunakan dalam memperbanyak tanaman secara vegetative (Stek), namun gunting stek lebih sering digunakan dalam memangkas tanaman, apabila tanaman tersebut terlalu rindang dan ingin di pangkas agar terlihat lebih cantik.

\section{g. Parang}

Parang yang digunakan dalam usaha tanaman hias adalah sebagai membersih gulma atau pun tumbuhan pengganggu yang sering menumpang hidup pada bunga ditempat usaha tanaman hias.Parang juga sering digunakan untuk memangkas bunga yang rindang.

\subsubsection{Tenaga Kerja}

Menurut Sumarsono (2009) bahwa semua orang yang melakukan kegiatan pekerjaan untuk diri sendiri atau orang lain dan menerima upah atau mereka yang sanggup bekerja. Pada usaha tanaman hias di Kelurahan Tembilahan Kota mempunyai satu orang tenaga kerja yang diupah setiap bulan dan gajinya telah ditentukan oleh pemilik usaha Kembang Lestari Garden.

\subsection{Teknik Usaha Tanaman Hias}

Usaha tanaman hias pada usaha kembang lestari garden adalah penjualan langsung kepada konsumen, di lakukan dengan beberapa cara yaitu :

Tanaman hias yang di jual oleh usaha kembang lestari garden di beli di luar daerah sampai diluar kota, namun tanaman hias tersebut bukanlah berasal dari bibit akan tetapi tanaman hias yang di beli sudah layak untuk di jual, adapun tanaman hias yang ukurannya masih kecil hanyalah beberapa batang saja dan tanaman tersebut tetap diperjual belikan, karena peminat akan tanaman hias yang masih mini atau kecil juga ada, sama halnya dengan bunga anggrek yang banyak macam nya namun yang paling banyak digemari pada usaha kembang lestari garden adalah anggrek Vanda selain harganyastandar bentuknya pun cantik. Semua tanaman pada usaha Kembng Lestari Garden setiap sore hari dan pagi hari di siram agar kebutuhan air pada terpenuhi, adapun pada segi pemupukan dilakukan hanya apabila ada tanaman yang kurang sehat seperti terkena hama dan penyakit lainnya, hal ini hanya sedikit terjadi.

Pada usaha Kembang Lestari Garden di Kelurahan Tembilahan Kota melakukan pembelian tanaman diluar kota yaitu pada kota bogor dan medan, tanaman yang di beli oleh pemilik usaha langsung di bawa pada 
tempat usaha dan biaya transportasinya ditanggung oleh penjual bibit tanaman hias yang ada di kota bogor dan medan, lalu usaha tanaman hias yang sudah sampai pada lokasi Kembang Lestari Garden ada yang memakai polybag dan ada juga yang memakai pot, namun hanya sedikit saja seperti bunga anggrek Vanda. tanaman hias yang masih dalam polybag di keluarkan kembali dan di masukkkan kedalam pot tergantung pada besar atau kecilnya tanaman, bagi tanaman yang masih kecil maka menggunakan pot yang kecil juga begitu juga dengan tanaman yang masih sedang dan yang besar akan di sesuaikan dengan ukuran pot.

Lalu tanaman hias di pasarkan dan penjualan tanaman hias bisa langsung datang di tempat usaha kembang lestari garden yang beralamat di Jalan Kembang Kelurahan termbilahan kota, namun terkadang juga di pasarkan dilapangan, biasanya lokasi penjualan di lapangan berada di depan Bank BNI, penjualan di lapangan tidak setiap hari di lakukan, hanya sekitar satu kali dalam satu bulan. Namun di tempat usaha melakukan jual beli setiap hari.

\subsection{Analisis Usaha Tanaman Hias}

\subsubsection{Biaya}

Menurut Mulyadi (2012) dalam artian luas biaya adalah pengorbanan sumber ekonomis yang di ukur dalam satuan uang, yang mungkin terjadi untuk mencapai tujuan tertentu. Dalam arti sempit biaya merupakan bagian dari harga pokok yang di korbankan dalam usaha untuk memperoleh penghasilan.Biaya dalam penelitian ini adalah seluruh biaya yang di keluarkan untuk usaha tanaman hias, baik biaya tetap maupun biaya tidak tetap.

\section{a. Biaya Tetap}

Menurut Mulyadi (2012) biaya tetap adalah biaya yang jumlah totalnya tetap konstan, tidak dipengaruhi oleh perubahan volume kegiatan atau aktivitas sampai dengan tingkat tertentu.Biaya tetap dalam usaha tanaman hias meliputi sekop, cangkul, gunting stek gembor dan biaya tenaga kerja keluarga.Jumlah biaya tetap dapat dilihat pada Tabel 1 .

Tabel 1. Biaya Tetap pada Usaha Tanaman Hias Per Periode (3 bulan)

\begin{tabular}{llcr}
\hline No & Komponen & Unit & \multicolumn{2}{c}{ Total (Rp) } \\
\hline 1 & Tenaga Kerja & Orang & 2.100 .000 \\
2 & Biaya Penyusutan & & \\
& a. Tempat Usaha & Unit & 62.500 \\
& b. Penyusutan Peralatan & Rp & 112.766 \\
\hline & Jumlah & & 2.275 .266
\end{tabular}

Sumber : data primer diolah tahun 2017

Tabel 1 di atas menunjukan bahwa biaya tetap berasal dari tempat usaha sebesar Rp.62.500,- per periode, upah tenaga kerja Rp.2.100.000,- per periode selama tiga bulan dan perbulannya adalah sebesar Rp.700.000,- biaya penyusutan alat sebesar Rp.112.766,per periode, hal ini senada dengan penelitian Wulandari

(2008) 
kontribusi terbesar pada biaya tetap adalah biaya tenaga kerja.

\section{b. Biaya Tidak Tetap}

Menurut Mulyadi (2012) biaya tidak tetap adalah biaya yang jumlah totalnya berubah secara sebanding (proposional) dengan perubahan volume kegiatan.Biaya variabel dapat dilihat pada Tabel 2.

Tabel 2. Biaya Tidak Tetap pada Usaha Tanaman Hias Per Periode (3 bulan)

\begin{tabular}{|c|c|c|c|c|}
\hline$\overline{\mathrm{No}}$ & Komponen & Satuan & Jumlah & Total (Rp) \\
\hline 1 & Tanah & Karung & 20 & 180.000 \\
\hline 2 & Bibit & Pot & 319 & 5.276 .000 \\
\hline \multirow[t]{4}{*}{3} & Pot & & & \\
\hline & a. Kecil & Buah & 200 & 1.000 .000 \\
\hline & b. Sedang & Buah & 35 & 700.000 \\
\hline & c. Besar & Buah & 40 & 1.400 .000 \\
\hline 4 & Pupuk & $\mathrm{Kg}$ & 95 & 272.500 \\
\hline 5 & Pestisida & Botol & 2 & 137.000 \\
\hline 6 & Tali & & 10 & 5.000 \\
\hline & Tot & & & 8.970 .500 \\
\hline
\end{tabular}

Sumber : data primer diolah tahun 2017

Tabel 2 di atas menunjukan bahwa biaya adalah di hitung per produksi selama tiga bulan (3 bulan), biaya tanah pada usaha tanaman hias di kelurahan tembilahan kota sebesar Rp.180.000,- per periode, total biaya bibit keseluruhan adalah sebesar Rp.5.276.000,- per periode, biaya pot adalah sebesar Rp.3.100.000,- per periode dan biaya pupuk adalah sebesar Rp.272.500,- per periode, sedangkan biaya pestisida adalah sebesar Rp.137.000,- per periode, dan biaya lain-lain adalah sebesar Rp.5.000,- per periode jadi total keseluruhan biaya tidak tetap adalah sebesar Rp.8.970.500,- per periode.
Sehingga dapat disimpulkan bahwa biaya terbesar yang dikeluarkan pada biaya tidak tetap adalah biaya bibit. Hal ini senada dengan penelitian yang di lakukan oleh Widyaningsih (2014) bahwa biaya yang di keluarkan terbesar adalah biaya pembelian bunga yaitu sebesar Rp.9.561.290,-.

\section{c. Biaya Total}

Biaya total tanaman hias meliputi seluruh biaya tetap dan tidak tetap. Besarnya biaya total usaha usaha tanaman hias dalam satu priode (3 Bulan) Tiga bulan dapat di lihat pada Tabel 3.

Tabel 3. Biaya Total Usaha Tanaman Hias Per Periode (3 bulan)

\begin{tabular}{llrc}
\hline No & \multicolumn{1}{c}{ Jenis Biaya } & Jumlah (Rp/Produksi) & Persentase (\%) \\
\hline 1 & Biaya Tetap & 2.275 .266 & 20,2 \\
2 & Biaya Tidak Tetap & 8.970 .500 & 79,8 \\
\hline \multicolumn{2}{l}{ Total } & 11.245 .766 & 100 \\
\hline
\end{tabular}

Sumber : data primer diolah tahun 2017 
Berdasarkan Tabel 3 di atas menunjukkan bahwa total biaya usaha tanaman hias satu periode adalah Rp.11.245.766,-- per periode atau 100 persen dan biaya tidak tetap yaitu sebesar Rp.8.970.500,per periode atau 79,8 persen sedangkan biaya tetap sebesar Rp.2.275.226,- per periode atau 20,2 persen. hal ini senada dengan penelitian Widyaningsih (2014) bahwa hasil penerimaan lebih besar di banding dengan total biaya, jumlah total biaya sebesar Rp.24.720.000,- dengan hasil jumlah rata-rata total biaya sebesar Rp.21.112.140,-.

\subsubsection{Pendapatan Kotor}

Pendapatan kotoryaitu seluruh pendapatan yang di peroleh dalam usaha selama satu periode, sedangkan pendapatan bersih yaitu hasil yang diperoleh dari total penjualan dari para pembeli dalam usaha yaitu selisih antara pendapatan bersih dan harga pokok penjualan, inilah yang dinamakan pendapatan kotor yang hasilnya belum dikurang dengan beban operasi lainnya dalam periode tertentu, pendapatan kotor dapat di lihat pada tabel 4 .

Tabel 4. Pendapatan Kotor Usaha Tanaman Hias Per Periode (3 bulan)

\begin{tabular}{llccr}
\hline No & \multicolumn{1}{c}{ Jenis Bunga } & Harga Jual & Jumlah & \multicolumn{1}{c}{ Total } \\
\hline 1 & Bunga Anggrek & 90.000 & 25 & 2.250 .000 \\
2 & Bunga Kamboja & 65.000 & 33 & 2.145 .000 \\
3 & Bunga Kertas & 75.000 & 45 & 3.375 .000 \\
4 & Bunga Mawar & 20.000 & 40 & 800.000 \\
5 & Bunga Sansevieria & 35.000 & 29 & 1.015 .000 \\
6 & Bunga Pucuk Merah & 25.000 & 47 & 1.175 .000 \\
7 & Bunga Aglonema & 35.000 & 25 & 875.000 \\
8 & Bunga Melati & 25.000 & 35 & 875.000 \\
9 & Bunga Soka & 30.000 & 30 & 900.000 \\
\hline \multicolumn{5}{c}{ Penerimaan } \\
\hline
\end{tabular}

Sumber : data primer diolah tahun 2017

Pendapatan kotor pada usaha tani tanaman hias di hitung dari jumlah keseluruhan tanaman hias yang terjual selama satu periode atau tiga bulan (3 bulan), lalu keseluruhan total dari tanaman hias yang terjual di jumlahkan sehingga di ketahui hasil penerimaan tanaman hias sebesar Rp.13.410.000 per periode,--

\subsubsection{Pendapatan Bersih}

Pendapatan bersih adalah perhitungan terakhir dari pendapatan kotor sehingga di dapatkan lah suatu pendapatan bersih, setiap pengusaha mempunyai tujuan yang sama bahwa dalam mengelola usahanya harus mendapatkan pendapatan bersih dan keuntungan. Keterangan pendapatan bersih dapat di lihat pada Tabel 5. 
Tabel 5. Pendapatan Bersih Usaha Tanaman Hias Per Periode (3 bulan)

\begin{tabular}{|c|c|c|}
\hline No & Keterangan & Jumlah \\
\hline 1 & Penerimaan & 13.410 .000 \\
\hline 2 & Total Biaya & 11.245 .766 \\
\hline & Pendapatan Bersih & 2.164 .234 \\
\hline
\end{tabular}

Sumber : data primer diolah tahun 2017

Pendapatan bersih pada usaha tani tanaman hias adalah jumlah dari keseluruhan total biaya tanaman hias yaitu penerimaan sebesar Rp.13.410.000,-per periode dan total biaya adalah sebesar Rp.11.245.766,- per periode sehingga hasil dari pendapatan bersih adalah sebesar Rp.2.164.234,-- per periode. Hal ini senada dengan penelitian Wulandari (2008) bahwa hasil penerimaan yang diperoleh adalah sebesar 15.557.500,--

\subsubsection{Efesiensi Usaha}

Efesiensi usaha merupakan perbandingan antara besarnya penerimaan yang diperoleh dan usaha tanaman hias dengan biaya total yang di keluarkan dengan menggunakan R/C Ratio (Return cost Ratio). Efesiensi usaha dapat di hitung dengan menggunakan $\mathrm{R} / \mathrm{C}$ Ratio, yaitu perbandingan antara penerimaan dan biaya yang dikeluarkan, dapat di lihat pada Tabel 6.

Tabel 6. Analisis Efesiensi Usaha Tanaman Hias Per Priode (3 bulan)

\begin{tabular}{|c|l|r|}
\hline NO & Uraian & Rata-rata/Produksi \\
\hline 1 & Total Penerimaan & 13.410 .000 \\
\hline 2 & Total Biaya & 11.245 .766 \\
\hline & Efesiensi Usaha & $\mathbf{1 , 2 1}$ \\
\hline
\end{tabular}

Sumber : data primer diolah tahun 2017

Berdasarkan Tabel 6 diatas, total penerimaan adalah sebesar Rp.13.410.000,- per periode dan total biaya keseluruhan adalah sebesar Rp.11.245.766,- per periode maka dapat di ketahui nilai efesiensi usaha tanaman hias sebesar 1,2 yang berarti usaha tanaman hias sudah di laksanakan secara efesiensi karena nilai $\mathrm{R} / \mathrm{C}>$ 1. 1,21 yang berarti $\mathrm{Rp} 1$ biaya yang di keluarkan dalam suatu usaha akan memberikan penerimaan sebesar 1,21 dan keuntungan sebesar 0,21.hal ini senada dengan penelitian Frisola (2010) bahwa hasil usaha tanaman hias Anggrek mendapatkan pendapatan bersih selama 3-4 bulan sebesar Rp.1.418.962 dengan efesiensi 2,00 yang berarti menguntungkan $\mathrm{di}$ karenakan $\mathrm{R} / \mathrm{C}>1$.

\section{KESIMPULAN DAN SARAN}

\subsection{Kesimpulan}

Dari hasil penelitian analisis usaha tanaman hias di Kota Tembilahan Kecamatan Tembilahan Kota kabupaten Indragiri Hilir dapat di ambil kesimpulan:

1. Total biaya yang dikeluarkan pada usaha Kembang Lestari Garden di Kelurahan Tembilahan 
Kecamatan Tembilahan Kota adalah sebesar Rp.11.245.766,-/ Periode.

2. Besar pendapatan bersih pada usaha Kembang Lestari Garden di Kelurahan Tembilahan Kecamatan Tembilahan Kota adalah sebesar Rp.2.164.234,-/ Periode.

3. Efesiensi usaha Kembang Lestari Garden Kelurahan tembilahan Kecamatan Tembilahan Kota sebesar 1,21 yang berarti usaha tanaman hias yang telah di lakukan sudah efesiensi karena nilai $\mathrm{R} / \mathrm{C}>1$. Nilai $\mathrm{R} / \mathrm{C} 1,21$ yang berarti $\mathrm{Rp} 1$ biaya yang di keluarkan dalam suatu usaha akan memberikan penerimaan sebesar 1,21 dan keuntungan sebesar 0,21 .

\subsection{Saran}

1. Perlu adanya penguatan produksi tanaman hias agar tercapai tingkat keuntungan yang maksimal.

2. Perlu dilakukannya perluasan usaha pada usaha tanaman hias agar usaha lebih berkembang.

\section{DAFTAR PUSTAKA}

Boediono.1984.

Usahatani.Penerbit alumni. Bandung.
Boediono. 1993. Perkembangan Usahatani Tanaman Hias. BPFE Universitas Gajah Mada, Yogyakarta.

Darmono.Dyah.2005. Agribisnis Teori dan Aplikasi. Penebar Swadaya. Jakarta.

Frisola.Emma. 2010.Besar Biaya Produksi Usahatani Anggrek Dan Anthurium. Medan.

Nazaruddin.B.A. 2005.Strategi Jitu Tanaman Hias Dengan SPSS.Penerbit Andi Yogyakarta.

Hendra. 2006. Anthurium Berkembang Dalam. Pot. Yogyakarta.

Hodisapoetra. 1973. Manajemen Pendapatan Usaha Dalam Bisnis Tanaman UI PRESS. Jakarta.

Juwita. 2007. Perkembang Biakan Bunga Melati.Bandung: Alpabeta.

Mosher.A.I. 1987.Menggerakkan dan Membangun Pertanian.Cetakkan II C.V. Yasaguna Jakarta.

Mulyadi. 1984. Perkembang Biakan Tanaman Hias Dalam Pot.Rineka Cipta. Jakarta. 